\title{
Correlation Between Nutritional Deficit and the Presence of Depressive Symptoms: Comparative Study Between Elderly Brazilians and Portuguese in Primary Health Care
}

\section{Gislani Acásia da Silva Toscano}

Universidade Federal do Rio Grande do Norte Centro de Ciencias da Saude

Anna Carolynna Vieira Cavalcante

Universidade Federal do Rio Grande do Norte Centro de Ciencias da Saude

Neidjany Patrícia Lima Torres

Universidade Federal do Rio Grande do Norte Centro de Ciencias da Saude

Jéssica Maria Arouca de Miranda

Universidade Federal do Rio Grande do Norte Centro de Ciencias da Saude

Bruno Araújo da Silva Dantas ( $\square$ bruno_asd90@hotmail.com )

Rua Alice Azevedo, 30, Apt. 804, Capim Macio, Natal-RN, Brazil. https://orcid.org/0000-0002-7442-0695

Maria Angélica Gomes Jacinto

Universidade Federal do Rio Grande do Norte Centro de Ciencias da Saude

Sandra Maria da Solidade Gomes Simões de Oliveira Torres

Universidade Federal do Rio Grande do Norte Centro de Ciencias da Saude

Thaiza Teixeira Xavier Nobre

Universidade do Estado do Rio Grande do Norte Faculdade de Ciencias da Saude

Eulália Maria Chaves Maia

Universidade Federal do Rio Grande do Norte Centro de Ciencias da Saude

Felismina Rosa Parreira Mendes

Universidade de Evora

Francisco Arnoldo Nunes de Miranda

Universidade Federal do Rio Grande do Norte Centro de Ciencias da Saude

Gilson de Vasconcelos Torres

Universidade Federal do Rio Grande do Norte Centro de Ciencias da Saude

Research article

Keywords: Depression, Elderly, Mental Health, Nutritional Status, Primary Health Care

Posted Date: August 31st, 2020

DOI: https://doi.org/10.21203/rs.3.rs-66052/v1

License: () (1) This work is licensed under a Creative Commons Attribution 4.0 International License. Read Full License 


\section{Abstract}

Background: Among the countless diseases that affect the world population, malnutrition has stood out in several social and demographic contexts; among them, there has been an exponential progression in elderly people, a population group that presents a strong tendency to develop depression and malnutrition. Data from the World Health Organization show that the worldwide prevalence of depressive disorders among elderly people is in the range of 10 to $20 \%$. Similarly, the prevalence of depression, in turn, combined with chronic diseases, accounts for $50 \%$ of premature mortality.

Objective: To compare the nutritional status and the level of depressive symptoms and to evaluate the correlation between both aspects in Brazilian and Portuguese elderly people assisted in Primary Health Care (PHC).

Methods: A cross-sectional, comparative study with a quantitative approach conducted among PHC elderly people in Brazil and Portugal. The sociodemographic and health questionnaire, Mini-Mental State Examination (MMSE), Geriatric Depression scale (GDS-15) and Mini-Nutritional Assessment (MNA) were used.

Results: We included 160 participants (110 Brazilians and 50 Portuguese) in the study. In this sample, $81.9 \%$ of participants had a risk of malnutrition or malnutrition and $45.0 \%$ of participants had mild depressive symptoms. There was a significant association and correlation in Brazil with the presence of a risk of malnutrition and mild symptoms of depression. Portugal also demonstrated a significant association, however, for the chance of not presenting alterations.

Conclusion: Our research showed that the risk of malnutrition or the presence of malnutrition was associated with the presence of depressive symptoms in the studied sample. In the intergroup comparison, among Brazilians, those at risk of malnutrition were more likely to have changes associated with depression, while for participants in Portugal, the odds ratio tended to show no changes, as the majority were individuals without nutritional or depressive demands. Screening and prevention measures should be emphasized in PHC to avoid the progression of symptoms in order to refer patients with medium and high complexity since this segment of the public is susceptible to malnutrition and depression.

\section{Background}

Among the countless diseases that affect the world population, malnutrition stands out in several social and demographic contexts, including when observing its exponential progression in elderly people, a population group that presents a strong tendency to develop depression, which is considered an important factor of depression, and is at risk for a worsening nutritional status $^{(1)}$. Compared to healthy individuals, individuals at severe risk for malnutrition, according to the study of Leiva Badosa, Badia Tahull (2), have longer hospital stays, in addition to a 4.4-times higher risk of long-term mortality ${ }^{(3)}$.

Another challenge imposed on the world population is the pandemic of the new coronavirus 2 (SARS-CoV-2), which started in December 2019, and has had devastating socioeconomic and health effects, forcing people to confine themselves in their homes in the first months of its spread. This pandemic has had unprecedented important psychological and emotional impacts and immense potential to worsen depressive symptoms in the population in the coming years $(4,5)$.

Data from the World Health Organization (WHO) show that the worldwide prevalence of depressive disorders among elderly people reaches 10 to $20 \%$ of these individuals. Similarly, the prevalence rate of depression, in turn, combined with chronic diseases accounts for $50 \%$ of premature mortality ${ }^{(6)}$. Malnutrition in elderly people, in turn, causes major economic losses, reaching $\$ 157$ billion annually in the United States of America (USA), affecting approximately three million elderly people ${ }^{(7)}$. In Brazil, an emerging country in South America, malnutrition is strongly associated with socioeconomic factors, such as low family income, female gender and low level of education ${ }^{(8)}$; these data are also similar when analysing depression in the same country ${ }^{(9)}$. Portugal, the country with the fourth highest number of elderly people in the European Union, presents scarce literature on nutritional assessments, especially for its geriatric population ${ }^{(10)}$; however, mental disorders are already a real concern in relation to the entire Portuguese population ${ }^{(11)}$. 
Depression is believed to be a component strongly associated with cognitive decline and malnutrition in older individuals ${ }^{(12,}$

13). With these disorders, neurodegenerative processes in specific brain regions and of genetic factors and inflammatory processes consequently alter nutritional status and cause dementia (cerebral atrophy), which can affect regions of the brain involved in regulating appetite and eating behaviour. Atrophy of the medial portion of the temporal cortex has been associated with low body mass index (BMI), suggesting a connection between damage to the limbic system and low body weight in neurodegenerative diseases. ${ }^{(14)}$. Because diagnosis is a multifactorial and complex process, the presence of a multidisciplinary team prepared to promote welcoming and assistance to this population is essential ${ }^{(15)}$.

In this context, Primary Health Care (PHC) emerges as the focus of individual and collective promotion and prevention measures, immersed in a multidisciplinary proposal( ${ }^{(16)}$. In both Brazil and Portugal, the Sistema Único de Saúde (SUS) and the Serviço Nacional de Saúde (SNS), respectively, provide the population with universal and free access to this general level of care ${ }^{(17-19)}$. PHC, which aims to promote close ties with the local community, is a privileged strategy for the development of screening, promotion and prevention measures involving diet, nutrition and mental disorders ${ }^{(16)}$. $\mathrm{PHC}$ was designed to prevent at least $60 \%$ of health problems, including depression ${ }^{(20)}$.

The screening, diagnosis and treatment of depression, despite the increase in its prevalence, remain deficient in clinical practice $^{(21)}$. However, when identifying the need for hospitalization due to malnutrition, elderly PHC users should be referred to secondary or tertiary care, a scenario in which the level of malnutrition in elderly people was found to be twice as high compared to those treated at the hospital itself ${ }^{(22)}$.

This problem, in addition to the growing incidence of depression and malnutrition in elderly PHC users, reinforces the importance of more effective measures, as elderly people constitute one of the groups most affected by the factors associated with these diseases. Elderly people are seen in health units, both in Brazil and in Portugal, because these services are among the main entry points for health in both countries. However, there are no specialist professionals, such as nutritionists and psychologists, because they are not mandatory members of teams of health professionals in basic health units $^{(17)}$. To provide support, the Family Health Support Center, FHSC ${ }^{(23)}$ (in Brazil), and the Shared Assistance Resource Units $^{(24)}$ (in Portugal) were designed to promote more effective referrals since the specialist professionals working in these centres work within communities. However, these centres operate at low capacity because they have few human resources and because they are not a mandatory in all areas covered by $\mathrm{PHC}^{(17)}$.

Therefore, we start from the hypothesis that the risk of malnutrition or the presence of malnutrition influences depressive symptoms among elderly people.

Our objective was to compare the nutritional status and the level of depressive symptoms and to evaluate the correlation between both aspects in Brazilian and Portuguese elderly people assisted in PHC.

\section{Methods}

\section{Ethical aspects}

We obtained approval, in Brazil, by the Comitê de Ética em Pesquisa of Hospital Universitário Onofre Lopes (CEP / HUOL) under opinion n 562.318 and Certificado de Apresentação para Apreciação Ética (CAAE) n 21996313.7.0000.5537. To carry out the study in Portugal, approval was obtained from the Research Ethics Committee for Research in the Areas of Human Health and Welfare at the University of Évora, under opinions No. 14011 and No. 17006. Before data collection, participants were asked to sign free and informed consent forms as a way of accepting participation in the study as well as authorizing the use of their information.

Design and Study Site 
A cross-sectional, comparative study using a quantitative approach was carried out with elderly people assisted in Primary Health Care (PHC) in Family Health Strategy Units (FHS) in the cities of Natal and Santa Cruz, both located in the State of Rio Grande do Norte, Brazil, and in Elderly Health Care Services (EHCS) in the coverage area of Family Health Units (FHU) in Eborae, Plaicie and Salus, linked to the regional health administration of the Municipality of Évora (Council Évora), in Portugal.

The following inclusion criteria were used: 60 years of age or older in Brazil(25) and 65 years of age or older in Portugal(26) according to the legislation in force in each country; registration in or being a user of a Family Health Unit in one of the study sites (Brazil / Portugal) for at least six months from the day of data collection; and a score of at least 17 points on the Mini Mental State Examination (MMSE) questionnaire, as suggested in its validation ${ }^{(27)}$. The following exclusion criteria were applied: history of limb amputation and/or a physical inability to remain upright for anthropometric measurements; medical diagnosis of an intellectual or mental disability.

\section{Instruments}

The following instruments were used in the present study: sociodemographic and health questionnaires, including closed questions (age, sex, education, family income and marital status, in addition to questions about health, such as the presence of chronic diseases); the MMSE questionnaire ${ }^{(28)}$, which is composed of several items that assess cognitive functions and is used as a cognitive screening tool; the Geriatric Depression Scale (GDS-15) ${ }^{(29)}$, which includes 15 objective and dichotomous questions (yes/no) about how the interviewee felt in the previous week using the following cut-off points to interpret the results: 0 to 5 points (no depression), 6 to 10 points (mild depression), and 11 to 15 points (severe depression); and the Mini Nutritional Assessment (MNA), which is composed of 18 questions whose total score differentiates the following groups: MNA > 24 (adequate nutritional status), MNA from 17 to 23.5 (at risk of malnutrition), and MNA $<17$ (total malnutrition) ${ }^{(30)}$

Participants' weight was measured using a portable digital platform scale with a maximum capacity of $150 \mathrm{~kg}$ and an accuracy of $100 \mathrm{~g}$. Height was measured with a 5-meter retractable steel tape measure on a wall on which the participants were standing, positioning their heads according to the Frankfurt plan and following the procedures of the Food and Nutrition Surveillance System (FNSS) ${ }^{(31)}$. The circumferences of the arm and calf were measured using an inelastic measuring tape with an accuracy of $1 \mathrm{~mm}^{(32)}$.

\section{Data collect}

Data were collected by undergraduate and graduate students in Nursing and Health Sciences with Master's and doctoral degrees, including nurses, nutritionists and physiotherapists who were previously instructed and trained, without remuneration, for the handling of anthropometric instruments and measurements. Training on the application of the instruments was carried out by nurses (for the sociodemographic questionnaire and GDS-15) and nutritionists (for MNA and anthropometry) who had previously used these questionnaires in clinical practice and/or in research. They did not participate in the study data collections.

The collections took place every fortnight for convenience between December 2015 and March 2016 and between December 2016 and January 2017 in Brazil. In Portugal, the collations took place between November 2017 and February 2018, with an average of 1 hour for each interview. Initially, participants were sought through an active search with the help of community health agents and nurses who worked in the coverage areas in Brazil and by two research assistants, both doctors from the São João de Deus School of Nursing (SJDSF), University of Évora (UE), in Portugal. Participants were contacted through the telephone numbers and addresses provided by their health services. After the invitations were sent, those who agreed to participate were included in the study, and the time and place for data collection were scheduled at their facilities and/or in health units in Brazil and at the Nossa Senhora de Fátima de Fátima Day Center) and Universidade Aberta Portuguesa (UAB) in Évora, as requested by Portuguese participants. Neither the participants nor the interviewers were blinded.

\section{Statistical analysis}

Page $4 / 13$ 
The data were tabulated with the aid of Microsoft® Excel 2016 (Microsoft Corporation, Washington, WA, USA). The Statistical Package for the Social Sciences (SPSS) software (IBM, Armonk, NY, USA) version 20.0 was used for statistical analysis of the data, and the normality of the data was assessed by the Shapiro-Wilk test, which indicated non-normality of the sample, followed by the descriptive and nonparametric Chi-Square test and Fisher's exact test for sociodemographic data and associations, respectively. In addition, Spearman's correlations and chance ratios between nutritional status and depressive symptoms were tested. The correlation levels (Spearman's Rho Test) were categorized as weak $(r<0.40)$, moderate $(r 0.40-0.49)$, and strong $(r>0.50)$. The significance of all the findings were established as $\rho$-value $\leq 0.05$.

\section{Results}

The study had a total sample of 160 participants, including 110 Brazilians and 50 Portuguese. Among the 118 Brazilians approached, eight participants were excluded, four for not reaching the minimum score of the MMSE, two for being registered in their health unit for less than six months and two for having physical limitations that did not allow the measurement of anthropometric data. In the Portuguese group, there was no exclusion of participants.

Table 1 shows the predominance of women (75.0\%) and younger individuals aged between 60 and 80 years (88.2\%), as well as the predominance of chronic diseases (84.4\%) in both countries. In Brazil, most participants had no partner (51.8\%) in contrast with the group in Portugal (44.0\%). In terms of income, 54.5\% of Brazilians earned 1 minimum wage or more, while

$76.0 \%$ of Portuguese showed a maximum income of up to 1 minimum wage ( $\rho$-value $<0.001$ ). In both groups, those with 1 to 5 years of schooling predominated $(\rho$-value $<0.001)$. 
Table 1

Sociodemographic and Health Characteristics and Classification of Nutritional Status and Depressive Symptoms $(n=160)$.

\begin{tabular}{|c|c|c|c|c|}
\hline \multirow[t]{2}{*}{ Sociodemographic and health characteristics } & Brazil & Portugal & Total & \multirow[t]{2}{*}{$\rho$-value } \\
\hline & $n(\%)$ & $n(\%)$ & $n(\%)$ & \\
\hline \multicolumn{5}{|l|}{ Sex } \\
\hline Female & $79(71.8)$ & $41(82.0)$ & $120(75.0)$ & \multirow[t]{2}{*}{$0.168^{*}$} \\
\hline Male & $31(28.2)$ & $9(18.0)$ & $40(25.0)$ & \\
\hline \multicolumn{5}{|l|}{ Age group } \\
\hline $60-80$ years & $98(89.1)$ & $43(86.0)$ & $141(88.2)$ & \multirow[t]{2}{*}{$0.575^{\star}$} \\
\hline $81-100$ years & $12(10.9)$ & $7(14.0)$ & $19(11.9)$ & \\
\hline \multicolumn{5}{|l|}{ Marital status } \\
\hline With live-in partner & $53(48.2)$ & $28(56.0)$ & $81(50.6)$ & \multirow[t]{2}{*}{$0.359 *$} \\
\hline Without live-in partner & $57(51.8)$ & $22(44.0)$ & $79(49.4)$ & \\
\hline \multicolumn{5}{|l|}{ Education } \\
\hline 1 to 5 years & $89(80.9)$ & $26(52.0)$ & $115(71.9)$ & \multirow[t]{3}{*}{$<0.001 *$} \\
\hline 6 to 10 years & $13(11.8)$ & $10(20.0)$ & $23(14.4)$ & \\
\hline 11 to 15 years & $8(7.3)$ & $14(28.0)$ & $22(13.8)$ & \\
\hline \multicolumn{5}{|l|}{ Income } \\
\hline Without income & $0(0.0)$ & $12(24.0)$ & $12(7.5)$ & \multirow[t]{3}{*}{$<0.001 * \star$} \\
\hline Up to $1 \mathrm{MW}$ & $50(45.5)$ & $38(76.0)$ & $88(55.0)$ & \\
\hline More than $1 \mathrm{MW}$ & $60(54.5)$ & $0(0.0)$ & $60(37.5)$ & \\
\hline \multicolumn{5}{|l|}{ Chronic diseases } \\
\hline Yes & $89(80.9)$ & $46(92.0)$ & $135(84.4)$ & \multirow[t]{2}{*}{$0.073^{\star \star}$} \\
\hline No & $21(19.1)$ & $4(8.0)$ & $25(15.6)$ & \\
\hline \multicolumn{5}{|l|}{ Nutritional status } \\
\hline Normal & $11(10.0)$ & $18(22.4)$ & $29(18.1)$ & \multirow[t]{2}{*}{$<0.001 *$} \\
\hline At risk of malnutrition/malnourished & $99(90.0)$ & $32(64.0)$ & $131(81.9)$ & \\
\hline \multicolumn{5}{|l|}{ Depressive symptoms } \\
\hline Without depression & $46(41.8)$ & $31(62.0)$ & $77(48.1)$ & \multirow[t]{3}{*}{$0.057^{*}$} \\
\hline Mild depression & $56(50.9)$ & $16(32.0)$ & $72(45.0)$ & \\
\hline Severe depression & $8(7.3)$ & $3(6.0)$ & $11(6.9)$ & \\
\hline
\end{tabular}

In Brazil, there was a higher frequency of participants with changes in both nutritional and depressive symptoms (Table 2), with a chance of changes of $17.5(\rho$-value $=0.001)$. In Portugal, the trend for individuals with normal nutritional status and without depressive symptoms, that is, the chance of not showing any changes, was $21.9(\rho$-value $=0.001)$. 
Table 2. Analyses of the Risk Estimate between the Mini Nutritional Assessment and the Geriatric Depression Scale 15.

\begin{tabular}{|c|c|c|c|c|c|c|c|c|c|}
\hline \multirow{4}{*}{$\begin{array}{l}\text { Depressive } \\
\text { symptoms }\end{array}$} & \multicolumn{9}{|c|}{ Nutritional changes } \\
\hline & \multicolumn{3}{|c|}{$\begin{array}{l}\text { Brazil } \\
(n=110)\end{array}$} & \multicolumn{3}{|c|}{ Portugal $(n=50)$} & \multicolumn{3}{|c|}{ Total $(n=160)$} \\
\hline & $A$ & G & \multirow{2}{*}{$\begin{array}{l}\mathrm{RC}(\mathrm{Cl} \\
95 \%)\end{array}$} & A & G & \multirow{2}{*}{$\begin{array}{l}\mathrm{RC}(\mathrm{Cl} \\
95 \%)\end{array}$} & A & G & \multirow{2}{*}{$\begin{array}{l}\mathrm{RC}(\mathrm{Cl} \\
95 \%)\end{array}$} \\
\hline & $\begin{array}{l}n \\
(\%)\end{array}$ & $n(\%)$ & & $n(\%)$ & $n(\%)$ & & $n(\%)$ & $n(\%)$ & \\
\hline \multirow[t]{2}{*}{$A^{a}$} & 10 & 36 & \multirow{4}{*}{$\begin{array}{l}17.5 \\
(2.2- \\
142.3)\end{array}$} & 17 & 14 & \multirow{4}{*}{$\begin{array}{l}21.9 \\
(2.6- \\
184.7)\end{array}$} & 27 & 50 & \multirow{4}{*}{$\begin{array}{l}21.9 \\
(4.98 \\
96.0)\end{array}$} \\
\hline & $(9.1)$ & $(32.7)$ & & & $(28.0)$ & & & $(31.3)$ & \\
\hline \multirow[t]{2}{*}{$G^{b}$} & 1 & 63 & & 1 & 18 & & 2 & 81 & \\
\hline & $(0.9)$ & $(57.3)$ & & $(2.0)$ & $(36.0)$ & & $(1.3)$ & $(50.6)$ & \\
\hline$\rho$-value* & \multicolumn{3}{|c|}{0.001} & \multicolumn{3}{|l|}{0.001} & \multicolumn{3}{|l|}{$<0.001$} \\
\hline
\end{tabular}

Table 3 shows that in Brazil, when analysing nutritional status and depression levels, the highest frequency was found for individuals with mild depressive symptoms and who were at risk of malnutrition ( $\rho$-value $=0.003$ ). In Portugal, individuals with normal nutritional status and without depression predominated ( $\rho$-value $=0.007)$. In general, the participants were at risk of malnutrition and mild depressive symptoms, with a significant difference in the analyses.

Table 3

Association between the Mini Nutritional Assessment and the Geriatric Depression Scale.

\begin{tabular}{|c|c|c|c|c|c|c|c|c|c|c|c|c|}
\hline \multirow{5}{*}{$\begin{array}{l}\text { Depressive } \\
\text { symptoms } \\
\text { Levels }\end{array}$} & \multicolumn{12}{|c|}{ Mini Nutritional Assessment - MNA } \\
\hline & \multicolumn{4}{|c|}{ Brazil $(n=110)$} & \multicolumn{4}{|c|}{ Portugal $(n=50)$} & \multicolumn{4}{|c|}{ Total $(n=160)$} \\
\hline & \multicolumn{12}{|c|}{ Nutritional status } \\
\hline & $\mathrm{N}$ & RM & M & \multirow{2}{*}{$\begin{array}{l}\rho^{-} \\
\text {value* }\end{array}$} & $\mathrm{N}$ & RM & M & \multirow{2}{*}{$\begin{array}{l}\rho- \\
\text { value }^{\star}\end{array}$} & $\mathrm{N}$ & RM & M & \multirow{2}{*}{$\begin{array}{l}\rho- \\
\text { value* }\end{array}$} \\
\hline & $\begin{array}{l}n \\
(\%)\end{array}$ & $n(\%)$ & $n(\%)$ & & $n(\%)$ & $n(\%)$ & & & $n(\%)$ & $n(\%)$ & $\begin{array}{l}n \\
(\%)\end{array}$ & \\
\hline Without & $\begin{array}{l}10 \\
(9.1)\end{array}$ & $\begin{array}{l}27 \\
(24.5)\end{array}$ & $\begin{array}{l}9 \\
(8.2)\end{array}$ & \multirow[t]{3}{*}{0.003} & $\begin{array}{l}17 \\
(34.0)\end{array}$ & $\begin{array}{l}14 \\
(28.0)\end{array}$ & - & \multirow[t]{3}{*}{0.007} & $\begin{array}{l}27 \\
(16.9)\end{array}$ & $\begin{array}{l}41 \\
(25.6)\end{array}$ & $\begin{array}{l}9 \\
(5.6)\end{array}$ & \multirow[t]{3}{*}{ <. 001} \\
\hline Mild & $\begin{array}{l}1 \\
(0.9)\end{array}$ & $\begin{array}{l}44 \\
(40.0)\end{array}$ & $\begin{array}{l}11 \\
(10.0)\end{array}$ & & $\begin{array}{l}1 \\
(2.0)\end{array}$ & $\begin{array}{l}14 \\
(28.0)\end{array}$ & $\begin{array}{l}1 \\
(2.0)\end{array}$ & & $\begin{array}{l}2 \\
(1.3)\end{array}$ & $\begin{array}{l}58 \\
(36.3)\end{array}$ & $\begin{array}{l}12 \\
(7.5)\end{array}$ & \\
\hline Severe & - & $\begin{array}{l}4 \\
(3.6)\end{array}$ & $\begin{array}{l}4 \\
(3.6)\end{array}$ & & - & $\begin{array}{l}3 \\
(6.0)\end{array}$ & - & & - & $\begin{array}{l}7 \\
(4.4)\end{array}$ & $\begin{array}{l}4 \\
(2.5)\end{array}$ & \\
\hline
\end{tabular}

In the analysis between nutritional status and depression, the correlation (Table 4) between both aspects was found to be significant and weak $(r=0.36)$ in individuals with the presence of nutritional changes and the presence of depressive symptoms ( $\rho$-value $<0.001$ ). Significance was also found in both countries; however, in Brazil, the parameters were directly proportional, that is, the more nutritional changes found, the more the depressive symptoms became evident, although with a weak correlation $(r=0.23)$. In Portugal, the results showed a trend towards normal nutritional status and without depression, with a strong correlation $(r=0.51)$. 
Table 4

Correlation between the Mini Nutritional Assessment and the Geriatric

Depression Scale.

\begin{tabular}{|c|c|c|c|c|c|}
\hline \multicolumn{6}{|c|}{ Mini Nutritional Assessment - MNA vs Geriatric Depression Scale - GDS-15 } \\
\hline \multicolumn{2}{|c|}{ Brazil $(n=110)$} & \multicolumn{2}{|c|}{ Portugal $(n=50)$} & \multicolumn{2}{|c|}{ Total $(n=160)$} \\
\hline$r$ & $\rho$-value* & $r$ & $\rho$-value & $r$ & $\rho$-value \\
\hline 0.23 & 0.013 & 0.51 & $<0.001$ & 0.36 & $<0.001$ \\
\hline
\end{tabular}

\section{Discussion}

Our study showed that the risk of malnutrition or the presence of malnutrition was associated with the presence of depressive symptoms in the studied sample. We also observed a predominance of participants at risk of malnutrition and mild depressive symptoms in Brazil, with a 17.4-fold chance of presenting nutritional or depressive changes and a significantly weak and positive correlation. In Portugal, we observed a tendency towards the absence of changes in both nutritional status and depressive symptoms, with a high chance of not having changes (21.9 times) but with a strong positive and significant correlation.

These findings may be related to the profile of greater female predominance and higher levels of education found among the Portuguese participants. A study conducted by Ghimire, Baral (33), who used a profile similar to ours, suggested that this reality is explained by the fact that compared with men, women seek more access to health services in addition to placing a greater value on the preservation of their autonomy in daily activities and self-care, a fact also influenced by a higher level of education.

The presence of chronic diseases in our sample indicated to be predominant in both scenarios, although there was no prominence between them, which may explain the fact that Brazilians had a considerable chance of developing nutritional and depressive changes. In this regard, it was estimated that individual who live with chronic diseases have a greater tendency to experience reduced quality of life and life expectancy due to the negative consequences exerted by them ${ }^{(34)}$. From a nutritional point of view, other studies have inferred that patients with chronic and malnourished diseases have a significant impairment in quality of life in addition to being more depressed and having lower life expectations ${ }^{(35,36)}$.

Regarding monthly income, in Portugal, some individuals did not have a regular income, and no participant had an income above the minimum wage, a situation opposite to that in Brazil, where participants had a higher level of income, despite their worse nutritional and depressive assessments. It is known that the quality of food is usually associated with how much income an individual or family has, and consequently, this aspect is inversely related to the risk of malnutrition/malnutrition ${ }^{(12,13)}$. Governmental measures for the selection and inclusion of these groups in income transfer programs, especially the Social Insertion Income (SII) in Portugal, can minimize the risk of malnutrition/malnutrition among elderly people, which aims to alleviate poverty, improve living conditions and health and encourage healthy habits ${ }^{(34)}$. However, these aspects need to be addressed by the PHC in an educational and consistent way by promoting an orientation towards healthy nutrition consistent with the reality of each individual, family and community ${ }^{(19)}$.

Other studies have shown that both low income and low education are associated with the risk of malnutrition and therefore may increase the risk of food insecurity $(34,37)$, which was one of our findings as well. Alvares and Amaral $(38)$ included 3,552 Portuguese individuals; of these, $16.5 \%$ exhibited food insecurity in association with the same variables ${ }^{(38)}$. Food insecurity is characterized as an individual who has a limited or uncertain possibility of acquiring food in a socially acceptable way or when the availability of food is compromised in relation to nutritional adequacy and safety ${ }^{(39)}$. Thus, these factors may have contributed to the highest percentage of participants with poor nutritional status found in the two groups in our study.

Page $8 / 13$ 
Research carried out in Switzerland showed a higher percentage of individuals with depression, who were more prone to risks of malnutrition and frailty ${ }^{(40)}$. This reality was indicated in the two countries we studied, but more clearly among Brazilians. Regarding this scenario, the importance of multidimensional interventions is increased to improve and/or minimize the nutritional deficits and depressive symptoms of the participants, as illustrated by successful past experiences in the Brazilian PHC scenario itself ${ }^{(9)}$. However, the coronavirus pandemic, which began in 2019 , is also projected to have effects on the general population, which includes elderly people, involving greater difficulty in circumventing the problem of depression in view of its substantial impact on mental health, which is generated by economic losses, deaths of family members, and other aspects affected in terms of behaviour, lifestyle and, consequently, nutritional status $(4,5)$.

Individuals in our study who were at risk of malnutrition had mild depressive symptoms in both countries, corroborating other findings in Taiwan, which also significantly associated the risk of malnutrition with depressive symptoms, where similar scales were used to measure these aspects, however with elderly people considered fragile ${ }^{(39)}$. Our results may be associated with poor eating habits due to loss of appetite, which is aggravated by decreased food intake and lack of palatability and usually causes malnutrition with the risk of increased malnutrition when associated with depression ${ }^{(41)}$.

In addition to showing an association and correlation between nutritional status and depressive symptoms, our study found a predominance of risk of malnutrition and mild depression in Brazil in comparison with Portugal. In a study conducted in Nepal, $10 \%$ of elderly people surveyed were malnourished, which accounted for $41 \%$ of the total effect of depression on quality of life, while depression had a $6 \%$ share of the total effect of malnutrition ${ }^{(33)}$. Similarly, the Brazilians in our sample appeared to suffer the same greater influence of malnutrition on depression than vice versa. That is, we observed a proportionally higher percentage of Brazilians with strictly nutritional demands than those who had only depressive symptoms.

Evidence indicates that good eating habits can mitigate depressive symptoms ${ }^{(42,43)}$. In the study of Jacka, 0 'Neil $(44), 32 \%$ of patients in two Australian hospitals who experienced moderate to severe depression and underwent a three-month dietary intervention showed significant improvements and remission of depressive symptoms. Therefore, the initiatives and interventions carried out in PHC units, which are gateways for the population, constitute a key strategy for health measures for active aging, which makes it possible to improve nutritional status and prevent malnutrition and depressive symptoms in medium and high complexity units. Active aging stands out as a concept of physical, social and mental well-being throughout life, that is, adopting healthy dietary, mental, exercise and leisure habits ${ }^{(45)}$.

PHC, with integrated care and networks, therefore, is vital for the promotion of active and healthy aging, as well as for the resolution of basic health demands in both countries. Collective measures are essential, mainly because they increase user participation in the educational process, team involvement with the participant and work optimization ${ }^{(17,21,46)}$. With the findings of two different scenarios, the importance of identifying changes in both nutritional status and mental health in the $\mathrm{PHC}$ scope is observed to improve the quality of life of the population towards healthy and active aging.

One of the limitations of this study was the sample size, especially of the group from Portugal, which suggests bias in the comparison between countries and impairment of the intergroup isonomy. In addition, the cross-sectional design of the study makes it difficult to establish causality. Thus, the inference power of our results is limited. Despite these obstacles, the methodological path we committed to was rigorously applied to seek the maximum similarity among the participants studied and, consequently, the greatest consistency of the data and its interpretations with respect to economic, social, cultural and cultural characteristics.

\section{Conclusions}

Our research showed that the risk of malnutrition or the presence of malnutrition was associated with the presence of depressive symptoms in the sample studied. In the intergroup comparison, among Brazilians, those at risk of malnutrition 
were more likely to have changes associated with depression, while for the participants from Portugal, the odds ratio tended to show no changes, as the majority were individuals without nutritional or depressive demands. In general, most participants were at risk of malnutrition/malnourishment, which was strongly associated with low income and low education. These findings allowed us to indicate our research hypothesis.

Screening and detecting malnutrition and depressive symptoms should be used as measures to prevent these problems. We believe that our results will help PHC professional teams to develop promotion and prevention measures not only for malnutrition and depression but also for other disorders in addition to public policies. The importance of the presence of a multidisciplinary team of nutritionists and psychologists as direct and indirect support in PHC is also emphasized to mitigate repercussions, thereby avoiding the need for hospitalizations and worsening cases.

Therefore, it is recommended to carry out additional studies, especially prospective studies, because of the imminent changes in the behaviour patterns of the world population due to the coronavirus pandemic.

\section{Abbreviations}

\section{BMI}

Body Mass Index; CEP:Comitê de Ética em Pesquisa; EHCS:Elderly Health Care Services; ESF:Family Health Strategy; USA:United States of America; FHSC:Family Health Support Center; FHU:Family Health Unit; FNSS:Food and Nutritional Surveillance System; GDS-15:Geriatric Depression Scale-15; HUOL:Hospital Universitário Onofre Lopes University Hospital; MAN:Mini Nutritional Assessment; MMSE:Mini-Mental State Examination; CAAE:Certificado de Apresentação para Apreciação Ética; PHC:Primary Health Care; SIl:Social Insertion Income; SJDN:São João de Deus School of Nursing; SNS:Serviço Nacional de Saúde; SUS:Sistema Único de Saúde; UAB:Universidade Aberta; UE:Universidade de Évora; WHO:World Health Organization;

\section{Declarations}

\section{Ethics approval and consent to participate}

We received approval from the Research Ethics Committee of Hospital Onofre Lopes (Brazil), opinion $n^{\circ} 562,318$ and by the Research Ethics Committee of the University of Évora (Portugal), with opinion n 14011, as well as the Ethics Committee for Scientific Research in Human Health and Welfare Areas of the University of Évora (Portugal), with n 17.006 / 2018.

Participants signed a free and informed consent form as a form of acceptance to participate in the study.

\section{Consent for publication}

Not applicable.

\section{Availability of data and materials}

The datasets used for the current study are available from the corresponding author upon reasonable request.

\section{Competing interests}

The authors declare that they have no competing interests.

\section{Funding}

Our research was funded by Conselho Nacional de Desenvolvimento Científico e Tecnológico (CNPQ), Call notice MCTI/CNPQ/Universal 14/2014 - Faixa B, with process number 454771/2014-2. 
GAST, BASD and MAGJ contributed to the study design, data acquisition and writing of the manuscript. JMAM, SMSGSOT, NPLT and ACVC contributed to the study design, acquisition and analysis of data and preparation of the manuscript. TTXN, FRPM, FANM, GVT and EMCM contributed to the analysis, draft and critical review of the manuscript. All the authors read and approved the final manuscript.

\section{Acknowledgements}

We are grateful to Thazia Costa, who made it possible for researchers to enter the Christmas scene, as well as her colleagues at her health unit; to the Family Health Strategy team of Santa Cruz, for allowing research to be carried out in their environment; to Professor Dr. João Manuel Galhanas Mendes, who welcomed the team of Brazilian researchers and students in Évora, Portugal, and contacted the local community possible to carry out our study.

\section{Author details}

${ }^{1-5} \mathrm{MSc}$ of the Post-Graduation Program in Health Sciences of the Universidade Federal do Rio Grande do Norte Natal-RN, Brazil; ${ }^{6}$ Nurse graduated from the Universidade Federal do Rio Grande do Norte, Natal-RN, Brazil; ${ }^{7}$ Doctor in Universidade Federal do Rio Grande do Norte Natal-RN, Brazil; ${ }^{8}$ Doctor of the Program in Health Sciences of the Faculdade de Ciências da Saúde do Trairí, Universidade Federal do Rio Grande do Norte Natal-RN, Brazil; ${ }^{9}$ Doctor in Universidade Federal do Rio Grande do Norte Natal-RN, Brazil; ${ }^{10} \mathrm{PhD}$ in sociology. Universidade de Évora. Évora, Portugal. Researcher of Comprehensive Health Research Centre (CHCR); ${ }^{11} \mathrm{PhD}$ of Psychiatric Nursing. Universidade Federal do Rio Grande do Norte Natal-RN, Brazil; ${ }^{12} \mathrm{PhD}$ of Nursing. Universidade Federal do Rio Grande do Norte Natal-RN, Brazil.

\section{References}

1. Granic A, Mendonca N, Hill TR, Jagger C, Stevenson EJ, Mathers JC, et al. Nutrition in the Very Old. Nutrients. 2018;10(3).

2. Leiva Badosa E, Badia Tahull M, Virgili Casas N, Elguezabal Sangrador G, Faz Mendez C, Herrero Meseguer I, et al. Hospital malnutrition screening at admission: malnutrition increases mortality and length of stay. Nutricion hospitalaria. 2017;34(4):907-13.

3. Sanchez-Rodriguez D, Marco E, Schott AM, Rolland Y, Blain H, Vazquez-Ibar O, et al. Malnutrition according to ESPEN definition predicts long-term mortality in general older population: Findings from the EPIDOS study-Toulouse cohort. Clinical nutrition. 2019;38(6):2652-8.

4. Wang C, Pan R, Wan X, Tan Y, Xu L, Ho CS, et al. Immediate Psychological Responses and Associated Factors during the Initial Stage of the 2019 Coronavirus Disease (COVID-19) Epidemic among the General Population in China. International journal of environmental research and public health. 2020;17(5).

5. Wang C, Pan R, Wan X, Tan Y, Xu L, Mclntyre RS, et al. A longitudinal study on the mental health of general population during the COVID-19 epidemic in China. Brain, behavior, and immunity. 2020.

6. Avasthi A, Grover S. Clinical Practice Guidelines for Management of Depression in Elderly. Indian journal of psychiatry. 2018;60(Suppl 3):341-S62.

7. Burks CE, Jones CW, Braz VA, Swor RA, Richmond NL, Hwang KS, et al. Risk Factors for Malnutrition among Older Adults in the Emergency Department: A Multicenter Study. J Am Geriatr Soc. 2017;65(8):1741-7.

8. Damiao R, Santos ADS, Matijasevich A, Menezes PR. Factors associated with risk of malnutrition in the elderly in southeastern Brazil. Revista brasileira de epidemiologia = Brazilian journal of epidemiology. 2017;20(4):598-610.

9. Dantas B, de Miranda JMA, Cavalcante ACV, Toscano G, Torres LSS, Rossignolo SCO, et al. Impact of multidimensional interventions on quality of life and depression among older adults in a primary care setting in Brazil: a quasiexperimental study. Revista brasileira de psiquiatria. 2020;42(2):201-8.

10. Madeira T, Peixoto-Placido C, Goulao B, Mendonca N, Alarcao V, Santos N, et al. National survey of the Portuguese elderly nutritional status: study protocol. BMC Geriatr. 2016;16:139. 
11. Antunes A, Frasquilho D, Azeredo-Lopes S, Neto D, Silva M, Cardoso G, et al. Disability and common mental disorders: Results from the World Mental Health Survey Initiative Portugal. European psychiatry: the journal of the Association of European Psychiatrists. 2018;49:56-61.

12. Mantzorou M, Vadikolias K, Pavlidou E, Serdari A, Vasios G, Tryfonos C, et al. Nutritional status is associated with the degree of cognitive impairment and depressive symptoms in a Greek elderly population. Nutr Neurosci. 2020;23(3):2019.

13. Muller FS, Meyer OW, Chocano-Bedoya P, Schietzel S, Gagesch M, Freystaetter G, et al. Impaired nutritional status in geriatric trauma patients. Eur J Clin Nutr. 2017;71(5):602-6.

14. Volkert D, Chourdakis M, Faxen-Irving G, Fruhwald T, Landi F, Suominen MH, et al. ESPEN guidelines on nutrition in dementia. Clinical nutrition. 2015;34(6):1052-73.

15. O'Reilly P, Lee SH, O'Sullivan M, Cullen W, Kennedy C, MacFarlane A. Assessing the facilitators and barriers of interdisciplinary team working in primary care using normalisation process theory: An integrative review. PloS one. 2017;12(5):e0177026.

16. Jego M, Abcaya J, Stefan DE, Calvet-Montredon C, Gentile S. Improving Health Care Management in Primary Care for Homeless People: A Literature Review. International journal of environmental research and public health. 2018;15(2).

17. Biscaia AR, Heleno LC. Primary Health Care Reform in Portugal: Portuguese, modern and innovative. Ciencia saude coletiva. 2017;22(3):701-12.

18. Brasil. Lei $n^{\circ}$ 8.080. In: Nacional C, editor Brasília-DF1990.

19. Brasil. Portaria $n^{\circ} 2.488$, de 21 de outubro de 2011. In: Saúde Md, editor. Brasília-DF2011.

20. Smith SM, Wallace E, O'Dowd T, Fortin M. Interventions for improving outcomes in patients with multimorbidity in primary care and community settings. Cochrane Database Syst Rev. 2016;3:CD006560.

21. Matias AG, Fonseca Mde A, Gomes Mde L, Matos MA. Indicators of depression in elderly and different screening methods. Einstein. 2016;14(1):6-11.

22. Paino Pardal L, Poblet IML, Rios Alvarez L. [The elderly living alone and malnutrition. SOLGER Study] Atencion primaria. 2017;49(8):450-8.

23. Brasil. Portaria n 154, de 24 de Janeiro de 2008. In: Saúde Md, editor. Brasília-DF2008.

24. República Dd. Decreto-Lei n. ${ }^{\circ}$ 28/2008. In: Portuguesa PdR, editor Lisboa-PT2008.

25. Brasil. Lei $n^{\circ} 10.741$, de $1^{\circ}$ de outubro de 2003. Dispõe sobre o Estatuto do Idoso e dá outras providências. In: República Pd, editor. Brasília-DF2003.

26. Kalache A, Gatti A. Active ageing: a policy framework. Advances in gerontology = Uspekhi gerontologii. 2003;11:7-18.

27. Bertolucci PHF, Brucki SMD, Campacci SR, Yara J. O Mini Exame do Estado Mental em uma população geral e Impacto da Escolaridade. Arq Neuropsiquiatr. 1994;52(1):7.

28. Murden RA, McRae TD, Kaner S, Bucknam ME. Mini-Mental State exam scores vary with education in blacks and whites. J Am Geriatr Soc. 1991;39(2):149-55.

29. Paradela EM, Lourenco RA, Veras RP. [Validation of geriatric depression scale in a general outpatient clinic]. Revista de saude publica. 2005;39(6):918-23.

30. Machado RS, Coelho MA, Veras RP. Validity of the portuguese version of the mini nutritional assessment in brazilian elderly. BMC Geriatr. 2015;15:132.

31. Brasil. Vigilância alimentar e nutricional - Sisvan: orientações básicas para a coleta, processamento, análise de dados e informação em serviços de saúde. In: Saúde Md, editor. Brasília-DF2004.

32. Landi F, Onder G, Russo A, Liperoti R, Tosato M, Martone AM, et al. Calf circumference, frailty and physical performance among older adults living in the community. Clinical nutrition. 2014;33(3):539-44.

33. Ghimire S, Baral BK, Pokhrel BR, Pokhrel A, Acharya A, Amatya D, et al. Depression, malnutrition, and health-related quality of life among Nepali older patients. BMC Geriatr. 2018;18(1):191.

Page $12 / 13$ 
34. Maseda A, Diego-Diez C, Lorenzo-Lopez L, Lopez-Lopez R, Regueiro-Folgueira L, Millan-Calenti JC. Quality of life, functional impairment and social factors as determinants of nutritional status in older adults: The VERISAUDE study. Clinical nutrition. 2018;37(3):993-9.

35. Acar Tek N, Karacil-Ermumcu MS. Determinants of Health Related Quality of Life in Home Dwelling Elderly Population: Appetite and Nutritional Status. J Nutr Health Aging. 2018;22(8):996-1002.

36. Jimenez-Redondo S, Beltran de Miguel B, Gavidia Banegas J, Guzman Mercedes L, Gomez-Pavon J, Cuadrado Vives C. Influence of nutritional status on health-related quality of life of non-institutionalized older people. J Nutr Health Aging. 2014;18(4):359-64.

37. Berkowitz SA, Seligman HK, Meigs JB, Basu S. Food insecurity, healthcare utilization, and high cost: a longitudinal cohort study. Am J Manag Care. 2018;24(9):399-404.

38. Alvares L, Amaral TF. Food insecurity and associated factors in the Portuguese population. Food nutrition bulletin. 2014;35(4):395-402.

39. Chen CT, Tung HH, Chen YC, Lee HF, Wang CJ, Lin WH. Depressive symptoms and nutritional status in the frail older adults. Arch Gerontol Geriatr. 2019;83:96-100.

40. Wiegand A, Zieger A, Staiger RD, Egli A, Freystatter G, Bischoff-Ferrari HA, et al. Association of depression with malnutrition, grip strength and impaired cognitive function among senior trauma patients. J Affect Disord. 2019;247:175-82.

41. Maynard M, Andrade L, Packull-McCormick S, Perlman CM, Leos-Toro C, Kirkpatrick SI. Food Insecurity and Mental Health among Females in High-Income Countries. International journal of environmental research and public health. 2018;15(7).

42. Goh CMJ, Abdin E, Jeyagurunathan A, Shafie S, Sambasivam R, Zhang YJ, et al. Exploring Singapore's consumption of local fish, vegetables and fruits, meat and problematic alcohol use as risk factors of depression and subsyndromal depression in older adults. BMC Geriatr. 2019;19(1):161.

43. Tolkien K, Bradburn S, Murgatroyd C. An anti-inflammatory diet as a potential intervention for depressive disorders: A systematic review and meta-analysis. Clinical nutrition. 2019;38(5):2045-52.

44. Jacka FN, O'Neil A, Opie R, Itsiopoulos C, Cotton S, Mohebbi M, et al. Correction to: A randomised controlled trial of dietary improvement for adults with major depression (the 'SMILES' trial). BMC Med. 2018;16(1):236.

45. Report of the World Health Organization. Active ageing: a policy framework. The aging male: the official journal of the International Society for the Study of the Aging Male. 2002;5(1):1-37.

46. Lourenco RA, Veras RP. [Mini-Mental State Examination: psychometric characteristics in elderly outpatients]. Revista de saude publica. 2006;40(4):712-9.

\section{Supplementary Files}

This is a list of supplementary files associated with this preprint. Click to download.

- CEPPortugal2.pdf

- CEPPortugal1.pdf

- CEPBrazil.pdf 